\title{
Violencia doméstica (Domestic violence)
}

Autora: Liliana Chaparro Moreno

DOI: 10.13140/RG.2.2.18671.25763

\section{Resumen:}

La violencia doméstica es un fenómeno que afecta a miles de personas en el mundo y que ha sido ampliamente estudiado. Este documento pretende reconocer desde un enfoque cienciométrico cuáles son los principales autores, instituciones, revistas y países que producen conocimiento académico sobre el tema. Lo anterior, especialmente orientado a identificar el campo en relación con los estudios de género.

\section{Summary:}

Domestic violence is a social phenomenon that affects thousands of people around the world. This document aims to recognize from a scientometric approach which are the main authors, institutions, and countries that produce academic knowledge on the subject. This, especially aimed at identifying the field in relation to gender studies.

\section{Palabras clave:}

Género, violencia, violencia doméstica, mujeres.

\section{Key words:}

Gender, violence, domestic violence, women.

La violencia contra las mujeres por parte de las parejas es un fenómeno que se engloba en el campo de estudios conocido como "gender studies". A este fenómeno se lo nombra de diferentes maneras, tanto en inglés como en español. Por ello, para reducir las búsquedas sin dejar por fuera los elementos principales, hice un primer análisis de las formas prevalentes de nombrarla, encontrando que la categoría de "domestic violence" era las que más resultados arrojaba con 21.004 documentos, respectivamente. Otras categorías como "partner violence" (17.339), "couple violence" (169 resultados), "husband violence" (57 resultados) e "intimate violence" (378 resultados), fueron descartadas porque en comparación con la primera son menos operativas.

En español se privilegió la búsqueda bajo la categoría de "violencia doméstica"

La búsqueda se realizó bajo el subtema "gender studies", que es un campo de estudios interdisciplinar. La plataforma Scimago indica que los países líderes en la investigación y producción científica del mundo en este campo son:

\begin{tabular}{|l|l|l|l|l|l|l|l|}
\hline $\begin{array}{l}\text { Ran } \\
\mathbf{k}\end{array}$ & Country & $\begin{array}{l}\text { Documen } \\
\text { ts }\end{array}$ & $\begin{array}{l}\text { Citable } \\
\text { documents }\end{array}$ & $\begin{array}{l}\text { Citation } \\
\mathbf{s}\end{array}$ & $\begin{array}{l}\text { Self- } \\
\text { citations }\end{array}$ & $\begin{array}{l}\text { Citations } \\
\text { document }\end{array}$ & $\begin{array}{l}\text { per } \\
\text { index }\end{array}$ \\
\hline
\end{tabular}


Métricas de Investigación: Cienciometría, Bibliometría y Datos Abiertos

\begin{tabular}{|l|l|l|l|l|l|l|l|}
\hline $\mathbf{1}$ & United States & 24718 & 23199 & $\begin{array}{l}32307 \\
7\end{array}$ & 195174 & 13,07 & 154 \\
\hline $\mathbf{2}$ & $\begin{array}{l}\text { United } \\
\text { Kingdom }\end{array}$ & 6712 & 6152 & 77853 & 30362 & 11,6 & 101 \\
\hline $\mathbf{3}$ & Canada & 3392 & 3207 & 37840 & 8245 & 11,16 & 76 \\
\hline $\mathbf{4}$ & Australia & 2600 & 2438 & 31494 & 7402 & 12,11 & 66 \\
\hline $\mathbf{5}$ & Brazil & 1416 & 1351 & 2810 & 1672 & 1,98 & 17 \\
\hline $\mathbf{6}$ & Sweden & 862 & 814 & 8310 & 2017 & 9,64 & 38 \\
\hline $\mathbf{7}$ & India & 851 & 762 & 3807 & 868 & 4,47 & 22 \\
\hline $\mathbf{8}$ & Spain & 748 & 703 & 3902 & 1258 & 5,22 & 26 \\
\hline $\mathbf{9}$ & Netherlands & 741 & 678 & 11137 & 1599 & 15,03 & 47 \\
\hline $\mathbf{1 0}$ & Germany & 740 & 683 & 6585 & 1037 & 8,9 & 38 \\
\hline $\mathbf{1 1}$ & New Zealand & 569 & 531 & 7683 & 1114 & 13,5 & 42 \\
\hline $\mathbf{1 2}$ & Israel & 538 & 508 & 5733 & 1424 & 10,66 & 36 \\
\hline $\mathbf{1 3}$ & South Africa & 497 & 459 & 3563 & 1463 & 7,17 & 29 \\
\hline $\mathbf{1 4}$ & France & 467 & 439 & 2029 & 300 & 4,34 & 31 \\
\hline $\mathbf{1 5}$ & Norway & 443 & 419 & 4339 & 807 & 9,79 & 29 \\
\hline $\mathbf{1 6}$ & Finland & 399 & 374 & 3597 & 753 & 9,02 & 26 \\
\hline $\mathbf{1 7}$ & Italy & 392 & 357 & 3674 & 787 & 9,37 & 20 \\
\hline $\mathbf{1 8}$ & China & 317 & 301 & 1694 & 589 & 5,34 & 23 \\
\hline $\mathbf{1 9}$ & Ireland & 282 & 256 & 2111 & 289 & 7,49 & 25 \\
\hline $\mathbf{2 0}$ & Hong Kong & 278 & 261 & 2432 & 491 & 8,75 & 23 \\
\hline $\mathbf{2 1}$ & Denmark & 275 & 259 & 2201 & 376 & 8 & 11 \\
\hline $\mathbf{2 2}$ & Colombia & 272 & 234 & 539 & 133 & 1,98 & \\
\hline & & & & & & 31 \\
\hline
\end{tabular}

Como se observa, Colombia ocupa el puesto 22 de producción mundial en el tema.

Las publicaciones más importantes a nivel mundial son (Scimago):

\begin{tabular}{|l|l|l|l|l|l|l|}
\hline $\begin{array}{l}\text { Ra } \\
\mathbf{n k}\end{array}$ & Title & Type & $\begin{array}{l}\text { SJR } \\
\text { Quarti } \\
\text { le }\end{array}$ & $\begin{array}{l}\text { H } \\
\text { ind } \\
\text { ex }\end{array}$ & Country & Publisher \\
\hline $\mathbf{1}$ & Gender and Society & journal & Q1 & 89 & United States & SAGE Publications \\
\hline $\mathbf{2}$ & $\begin{array}{l}\text { Psychology of Women } \\
\text { Quarterly }\end{array}$ & journal & Q1 & 78 & United States & SAGE Publications \\
\hline $\mathbf{3}$ & $\begin{array}{l}\text { Biology of Sex Differences } \\
\mathbf{4}\end{array}$ & journal & Q1 & 30 & $\begin{array}{l}\text { United } \\
\text { Kingdom }\end{array}$ & BioMed Central \\
\hline $\mathbf{5}$ & $\begin{array}{l}\text { Psychology of Sexual } \\
\text { Orientation and Gender } \\
\text { Diversity }\end{array}$ & journal & Q1 & 19 & United States & $\begin{array}{l}\text { American Psychological } \\
\text { Association Inc. }\end{array}$ \\
\hline $\mathbf{6}$ & $\begin{array}{l}\text { Journal of Sex Research } \\
\text { Journal }\end{array}$ & Q1 & 49 & United States & SAGE Publications \\
\hline $\mathbf{7}$ & $\begin{array}{l}\text { Politics \& Gender } \\
\mathbf{8}\end{array}$ & $\begin{array}{l}\text { Social Politics } \\
\mathbf{9}\end{array}$ & Sex Roles & 92 & $\begin{array}{l}\text { United } \\
\text { Kingdom }\end{array}$ & Taylor \& Francis \\
\hline $\mathbf{9}$ & journal & Q1 & 48 & $\begin{array}{l}\text { United } \\
\text { Kingdom }\end{array}$ & $\begin{array}{l}\text { Cambridge University } \\
\text { Press }\end{array}$ \\
\hline
\end{tabular}


Métricas de Investigación: Cienciometría, Bibliometría y Datos Abiertos

\begin{tabular}{|l|l|l|l|l|l|l|}
\hline $\mathbf{1}$ & Journal of Bisexuality & journal & Q1 & 29 & $\begin{array}{l}\text { United } \\
\text { Kingdom }\end{array}$ & Taylor \& Francis \\
\hline
\end{tabular}

En Latinoamérica las principales publicaciones son las que se presentan a continuación, siendo una revista colombiana la que ocupa el primer lugar (Scimago):

\begin{tabular}{|l|l|l|l|l|l|l|}
\hline $\begin{array}{l}\text { Ran } \\
\mathbf{k}\end{array}$ & Title & Type & $\begin{array}{l}\text { SJR } \\
\text { Qua } \\
\text { rtile }\end{array}$ & $\begin{array}{l}\mathbf{H} \\
\text { inde } \\
\mathbf{x}\end{array}$ & Country & Publisher \\
\hline $\mathbf{1}$ & $\begin{array}{l}\text { Revista de Estudios } \\
\text { Sociales }\end{array}$ & journal & Q3 & 8 & $\begin{array}{l}\text { Colombi } \\
\text { a }\end{array}$ & Universidad de los Andes \\
\hline $\mathbf{2}$ & $\begin{array}{l}\text { Cadernos de } \\
\text { Pesquisa }\end{array}$ & journal & Q3 & 13 & Brazil & Fundacao Carlos Chagas \\
\hline $\mathbf{3}$ & Estudos Feministas & journal & Q3 & 13 & Brazil & $\begin{array}{l}\text { Universidade Federal de Santa } \\
\text { Catarina }\end{array}$ \\
\hline $\mathbf{4}$ & Cadernos pagu & journal & Q3 & 8 & Brazil & $\begin{array}{l}\text { Universidade Estadual de } \\
\text { Campinas, Instituto de Filosofia e } \\
\text { Ciencias Humanas, Pagu, Centro } \\
\text { de Estudos de Genero }\end{array}$ \\
\hline
\end{tabular}

Al buscar por "domestic violence" en la plataforma Scopus, encontramos 21.004 documentos, siendo el año de mayor producción el 2019, tal como se aprecia en la siguiente gráfica:

Documents by year

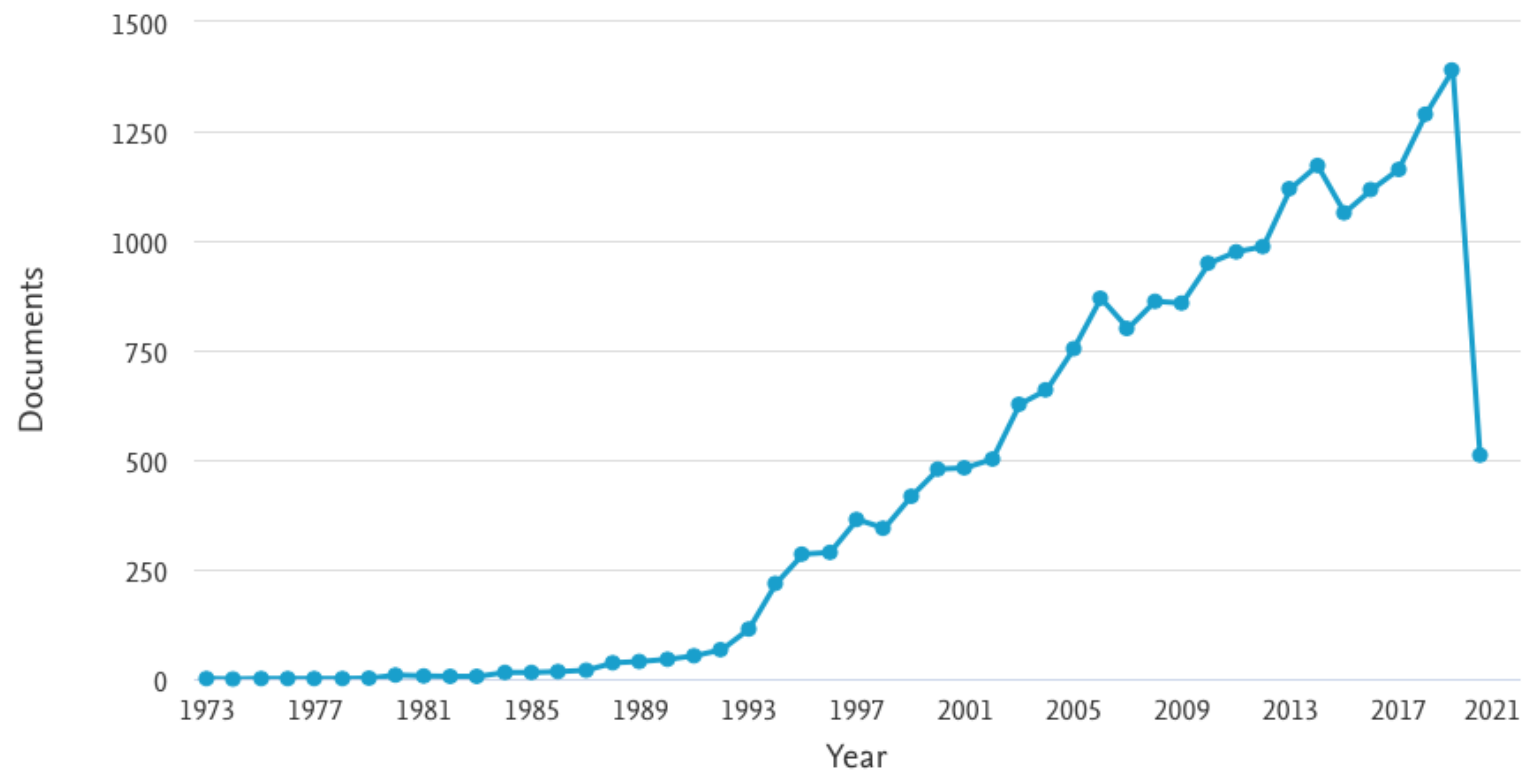

A continuación se presenta el listado de los autores con mayor producción en el tema, de acuerdo con la plataforma Scopus: 
Métricas de Investigación: Cienciometría, Bibliometría y Datos Abiertos

Documents by author

Compare the document counts for up to 15 authors.

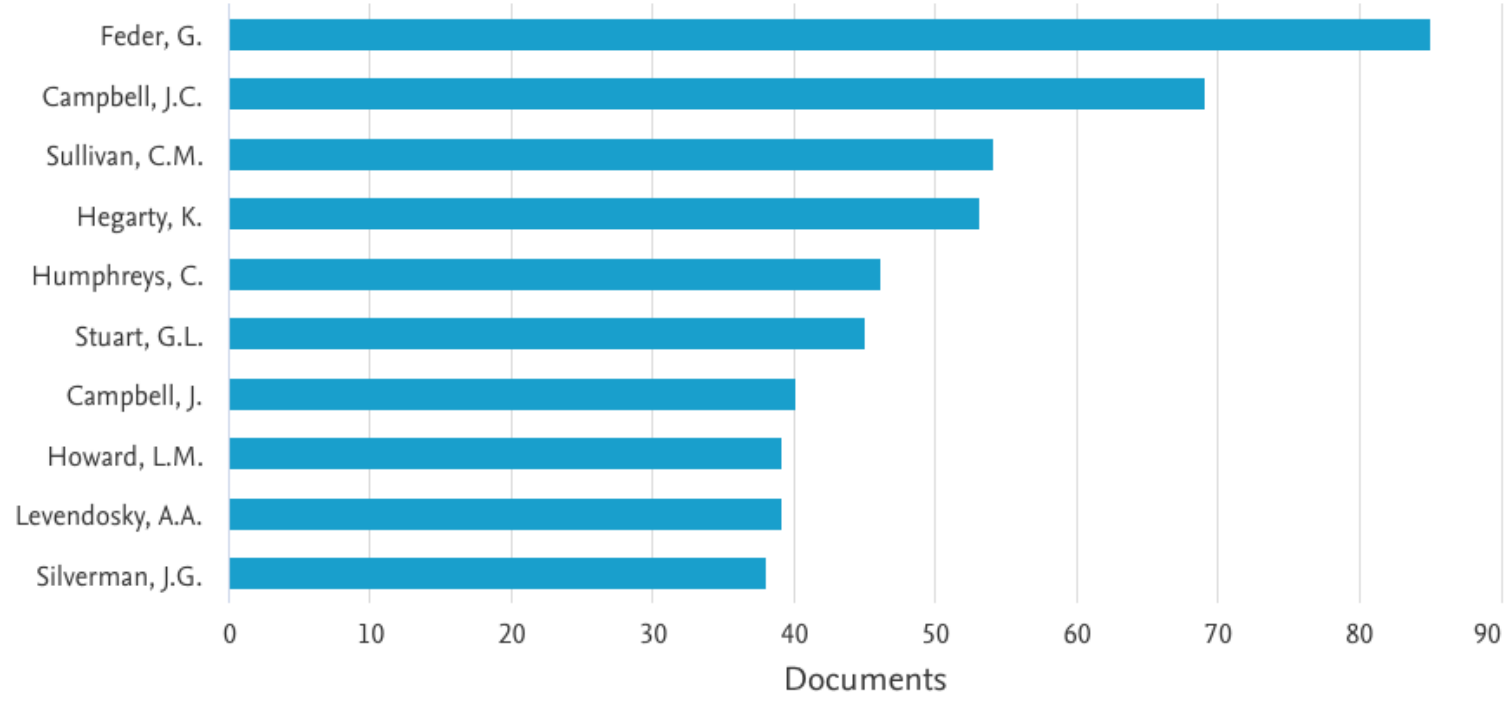

Las instituciones que más han apoyado las publicaciones, de acuerdo con Scopus, son:

Documents by funding sponsor

Compare the document counts for up to 15 funding sponsors.

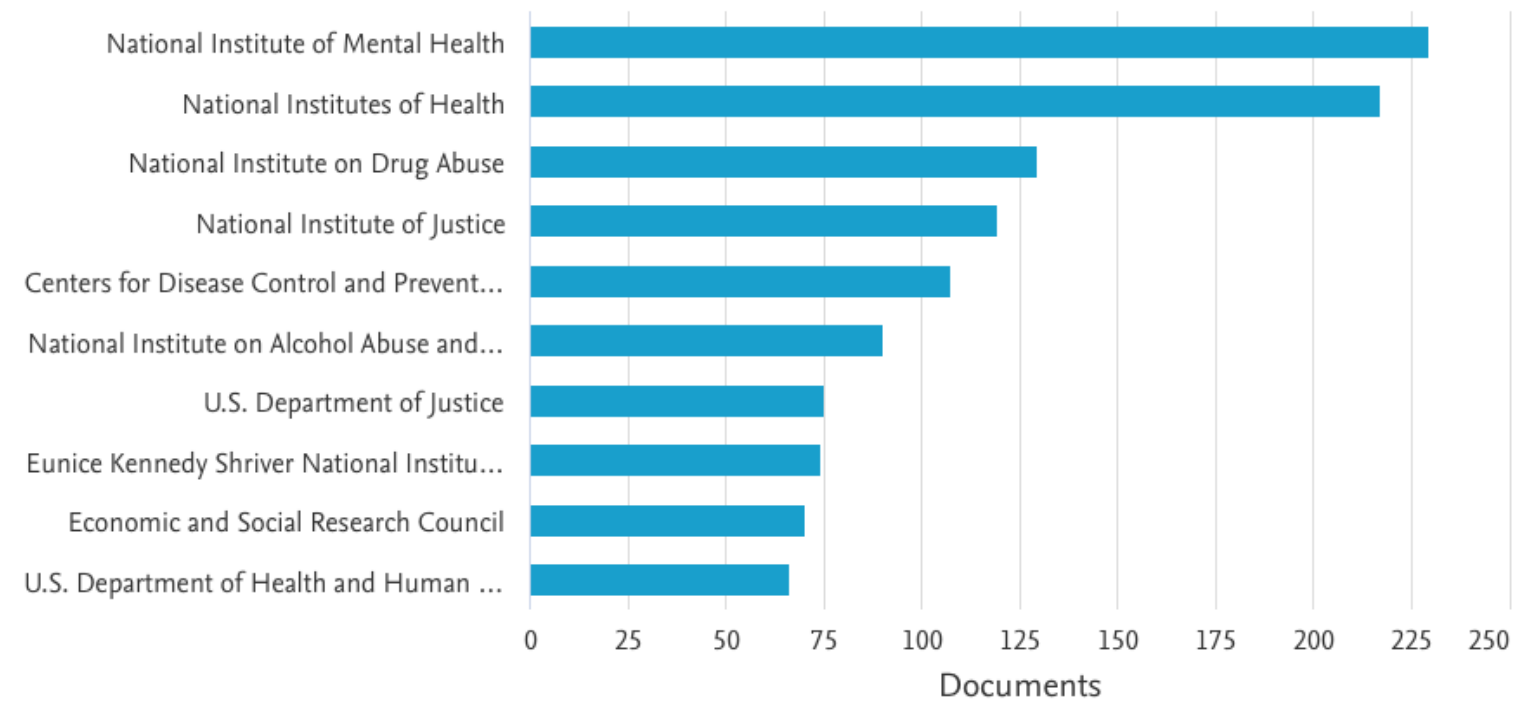

La tipología documental que más se ha publicado de acuerdo con Scopus es la de artículos, tal como se observa en la gráfica: 
Métricas de Investigación: Cienciometría, Bibliometría y Datos Abiertos

Documents by type

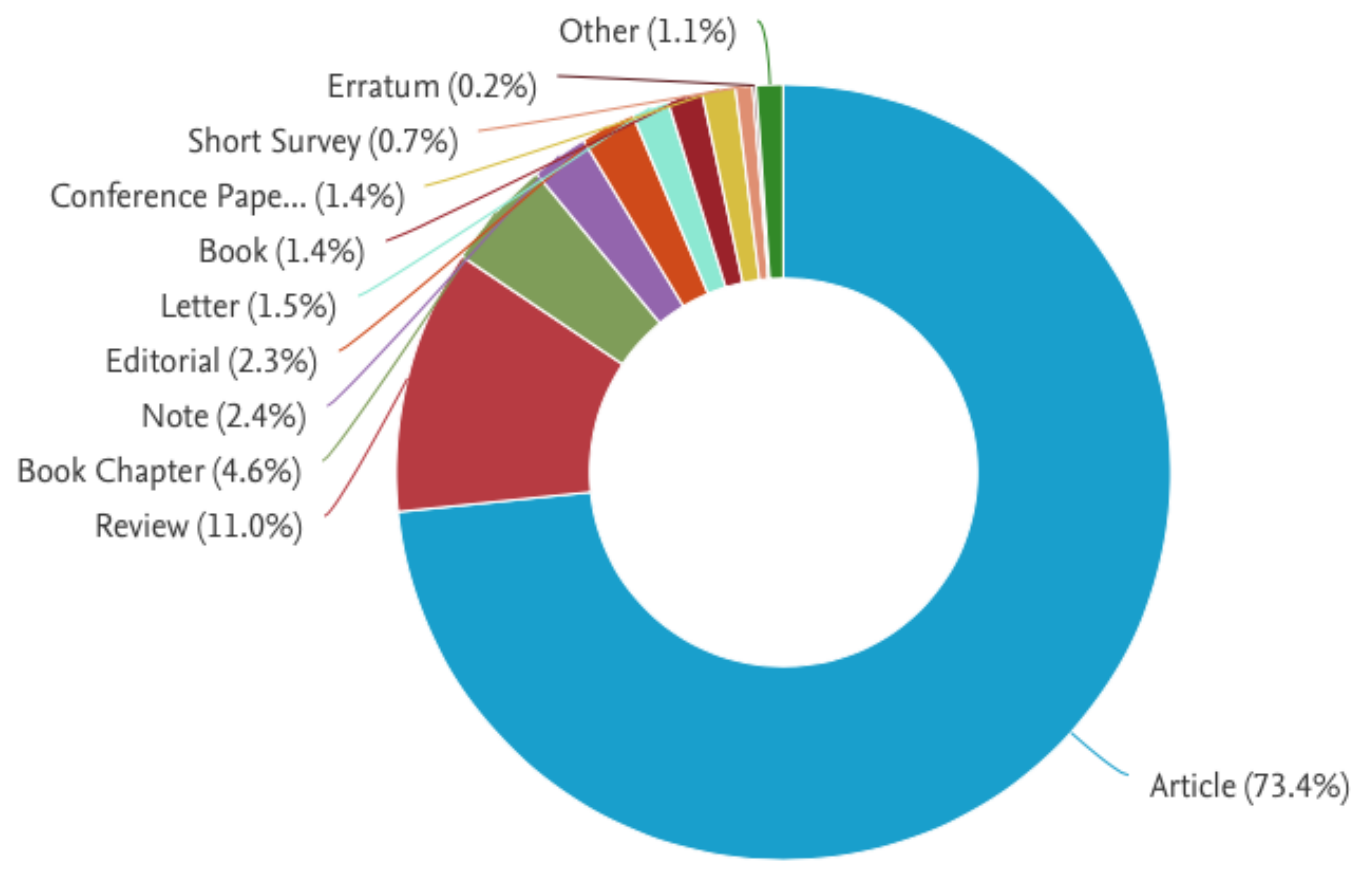

Al hacer la búsqueda en Latinoamérica por la fuente LaReferencia, encontramos que los estudios sobre "violencia doméstica" son liderados significativamente por Brasil, seguidos de Perú y Colombia. Del total de 1779 documentos publicados, 1593 fueron publicados en Brasil:

\begin{tabular}{|lr|}
\hline País & \multicolumn{1}{|c|}{} \\
\hline Brasil & 1,593 \\
\hline Perú & 51 \\
\hline Colombia & 45 \\
\hline Costa Rica & 25 \\
\hline Chile & 19 \\
\hline Argentina & 15 \\
\hline México & 12 \\
\hline Ecuador & 10 \\
\hline Uruguay & 9 \\
\hline
\end{tabular}

En Latinoamérica quienes lideran la producción en violencia doméstica son Nadirlene Gomes, Claudia Moraes, Michael Reichenheim, Lilia Schraiber y Suely Deslandes (LaReferencia): 
Métricas de Investigación: Cienciometría, Bibliometría y Datos Abiertos

\begin{tabular}{|ll|}
\hline \multicolumn{1}{|c|}{ Autor } & $\boldsymbol{\Delta}$ \\
\hline Gomes,Nadirlene Pereira & 9 \\
\hline Moraes,Claudia Leite & 9 \\
\hline Reichenheim,Michael Eduardo & 9 \\
\hline Schraiber,Lilia Blima & 9 \\
\hline Deslandes, Suely Ferreira & 8 \\
\hline Diniz,Normélia Maria Freire & 6 \\
\hline Garbin,Cléa Adas Saliba & 6 \\
\hline Gomes, Romeu & 6 \\
\hline Apostólico,Maíra Rosa & 5 \\
\hline Assis,Simone Gonçalves de & 5 \\
\hline & \\
\hline
\end{tabular}

Las instituciones que más publican en Latinoamérica sobre "violencia doméstica" son la Universidade de São Paulo, el Superior Tribunal de Justiça, la Fundação Oswaldo Cruz, la Universidade Federal de Santa Catarina y la Universidade Federal do Rio Grande do Sul (LaReferencia):

\begin{tabular}{|lr|}
\hline Ẩ Institución & $\boldsymbol{\Delta}$ \\
\hline Universidade de São Paulo & 195 \\
\hline Superior Tribunal de Justiça & 163 \\
\hline Fundação Oswaldo Cruz & 93 \\
\hline $\begin{array}{l}\text { Universidade Federal de Santa } \\
\text { Catarina }\end{array}$ \\
\hline $\begin{array}{l}\text { Universidade Federal do Rio Grande } \\
\text { do Sul }\end{array}$ \\
\hline Universidade de Brasilia \\
\hline Universidade Estadual Paulista \\
\hline Universidade Estadual de Campinas & 49 \\
\hline ABRASCO
\end{tabular}


Métricas de Investigación: Cienciometría, Bibliometría y Datos Abiertos

En su mayoría, los documentos publicados en Latinoamérica son artículos (993), tesis de maestría (594) y tesis doctorales (175) (LaReferencia):

\begin{tabular}{|lr|}
\hline 㕩 & \multicolumn{1}{|c|}{ Tipo de recurso } \\
\hline artículo & 993 \\
\hline tesis de maestría & 594 \\
\hline tesis doctoral & 175 \\
\hline informe técnico & 17 \\
\hline
\end{tabular}

A continuación presento las mediciones cienciométricas de la búsqueda "Domestic violence" (búsqueda el 26 de mayo de 2020):

\begin{tabular}{|c|c|c|c|c|c|}
\hline Indicador & Descripción & Fuente & 2018 & 2019 & 2020 \\
\hline $\begin{array}{l}\text { Indicador de } \\
\text { producción }\end{array}$ & $\begin{array}{l}\text { Total } \\
\text { artículos }\end{array}$ & Scopus & 911 & 1151 & 439 \\
\hline $\begin{array}{l}\text { Indicador de } \\
\text { producción }\end{array}$ & Total de libros & Scopus & 17 & 4 & 0 \\
\hline $\begin{array}{l}\text { Indicador de } \\
\text { producción }\end{array}$ & $\begin{array}{ll}\text { Total } & \text { de } \\
\text { capítulos } & \text { de } \\
\text { libros } & \end{array}$ & Scopus & 83 & 20 & 0 \\
\hline $\begin{array}{l}\text { Indicador de } \\
\text { producción }\end{array}$ & $\begin{array}{ll}\text { Total } & \text { de } \\
\text { Conference } & \\
\text { Paper } & \end{array}$ & Scopus & 16 & 15 & 2 \\
\hline $\begin{array}{l}\text { Indicador de } \\
\text { producción }\end{array}$ & $\begin{array}{l}\text { Principal entidad } \\
\text { financiadoras }\end{array}$ & Scopus & $\begin{array}{l}\text { National } \\
\text { Institutes of } \\
\text { Health }\end{array}$ & $\begin{array}{l}\text { National } \\
\text { Institutes of } \\
\text { Health }\end{array}$ & $\begin{array}{l}\text { National } \\
\text { Institutes of } \\
\text { Health }\end{array}$ \\
\hline $\begin{array}{l}\text { Indicador de } \\
\text { producción }\end{array}$ & $\begin{array}{l}\text { Principal país de } \\
\text { publicación (sin } \\
\text { incluir el país de } \\
\text { origen) }\end{array}$ & Scopus & $\begin{array}{l}\text { Estados } \\
\text { Unidos }\end{array}$ & $\begin{array}{l}\text { Estados } \\
\text { Unidos }\end{array}$ & Estados Unidos \\
\hline $\begin{array}{l}\text { Indicador de } \\
\text { producción }\end{array}$ & $\begin{array}{l}\text { Autor con mayor } \\
\text { publicaciones }\end{array}$ & Scopus & Feder, G. & Feder, G. & Goodman, L.A. \\
\hline $\begin{array}{l}\text { Indicador de } \\
\text { producción }\end{array}$ & $\begin{array}{l}\text { Total de } \\
\text { artículos }\end{array}$ & WOS & 1132 & 1323 & 438 \\
\hline $\begin{array}{l}\text { Indicador de } \\
\text { producción }\end{array}$ & Total de libros & WOS & 0 & 0 & 0 \\
\hline $\begin{array}{l}\text { Indicador de } \\
\text { producción }\end{array}$ & $\begin{array}{ll}\text { Total } & \text { de } \\
\text { capítulos } & \text { de } \\
\text { libros } & \end{array}$ & WOS & 3 & 1 & 0 \\
\hline $\begin{array}{l}\text { Indicador de } \\
\text { producción }\end{array}$ & $\begin{array}{l}\text { Total de } \\
\text { Conference } \\
\text { Paper (Meeting } \\
\text { abstract) }\end{array}$ & WOS & 17 & 15 & 0 \\
\hline $\begin{array}{l}\text { Indicador de } \\
\text { producción }\end{array}$ & $\begin{array}{l}\text { Principal entidad } \\
\text { financiadoras }\end{array}$ & WOS & $\begin{array}{l}\text { United } \\
\text { States } \\
\text { Department }\end{array}$ & $\begin{array}{l}\text { United States } \\
\text { Department } \\
\text { of Health }\end{array}$ & $\begin{array}{l}\text { United States } \\
\text { Department of }\end{array}$ \\
\hline
\end{tabular}


Métricas de Investigación: Cienciometría, Bibliometría y Datos Abiertos

\begin{tabular}{|c|c|c|c|c|c|}
\hline & & & $\begin{array}{l}\text { of Health } \\
\text { Human } \\
\text { Services }\end{array}$ & $\begin{array}{l}\text { Human } \\
\text { Services }\end{array}$ & $\begin{array}{l}\text { Health Human } \\
\text { Services }\end{array}$ \\
\hline $\begin{array}{l}\text { Indicador de } \\
\text { producción }\end{array}$ & $\begin{array}{l}\text { Principal país de } \\
\text { publicación (sin } \\
\text { incluir el país de } \\
\text { origen) }\end{array}$ & WOS & $\begin{array}{l}\text { Estados } \\
\text { Unidos }\end{array}$ & $\begin{array}{l}\text { Estados } \\
\text { Unidos }\end{array}$ & Estados Unidos \\
\hline $\begin{array}{l}\text { Indicador de } \\
\text { producción }\end{array}$ & $\begin{array}{l}\text { Autor con mayor } \\
\text { publicaciones }\end{array}$ & WOS & Feder G. & Feder G. & Hegarty K. \\
\hline $\begin{array}{l}\text { Indicador de } \\
\text { producción }\end{array}$ & $\begin{array}{l}\text { Total de } \\
\text { artículos }\end{array}$ & $\begin{array}{l}\text { LaRefere } \\
\text { ncia }\end{array}$ & 44 & 28 & 7 \\
\hline $\begin{array}{l}\text { Indicador de } \\
\text { producción }\end{array}$ & Total de libros & $\begin{array}{l}\text { LaRefere } \\
\text { ncia }\end{array}$ & 0 & 0 & 0 \\
\hline $\begin{array}{l}\text { Indicador de } \\
\text { producción }\end{array}$ & $\begin{array}{l}\text { Total Tesis } \\
\text { Doctorado }\end{array}$ & $\begin{array}{l}\text { LaRefere } \\
\text { ncia }\end{array}$ & 9 & 2 & 0 \\
\hline $\begin{array}{l}\text { Indicador de } \\
\text { producción }\end{array}$ & $\begin{array}{l}\text { Total de } \\
\text { Maestría }\end{array}$ & $\begin{array}{l}\text { LaRefere } \\
\text { ncia }\end{array}$ & 27 & 19 & 0 \\
\hline $\begin{array}{l}\text { Indicador de } \\
\text { producción }\end{array}$ & $\begin{array}{l}\text { Principal país de } \\
\text { publicación (sin } \\
\text { incluir el país de } \\
\text { origen) }\end{array}$ & $\begin{array}{l}\text { LaRefere } \\
\text { ncia }\end{array}$ & Brasil (70) & Brasil (44) & Brasil (7) \\
\hline $\begin{array}{l}\text { Indicador de } \\
\text { producción }\end{array}$ & $\begin{array}{l}\text { Autor con mayor } \\
\text { publicaciones }\end{array}$ & $\begin{array}{l}\text { LaRefere } \\
\text { ncia }\end{array}$ & $\begin{array}{l}\text { Colina } \\
\text { Moreno, } \\
\text { Mary Isabel }\end{array}$ & $\begin{array}{l}\text { Albertim } \\
\text { Renata }\end{array}$ & $\begin{array}{l}\text { Aguiar, Ricardo } \\
\text { Saraiva }\end{array}$ \\
\hline $\begin{array}{l}\text { Indicador de } \\
\text { producción }\end{array}$ & $\begin{array}{ll}\text { Total } & \text { de } \\
\text { artículos } & \end{array}$ & $\begin{array}{l}\text { Scielo } \\
\text { (búsqued } \\
\text { a en } \\
\text { español) }\end{array}$ & 55 & - & - \\
\hline $\begin{array}{l}\text { Indicador de } \\
\text { producción }\end{array}$ & $\begin{array}{l}\text { Principal entidad } \\
\text { financiadoras }\end{array}$ & Scielo & - & - & - \\
\hline $\begin{array}{l}\text { Indicador de } \\
\text { producción }\end{array}$ & $\begin{array}{l}\text { Principal país de } \\
\text { publicación (sin } \\
\text { incluir el país de } \\
\text { origen) }\end{array}$ & Scielo & - & - & - \\
\hline $\begin{array}{l}\text { Indicador de } \\
\text { producción }\end{array}$ & $\begin{array}{l}\text { Autor con mayor } \\
\text { publicaciones }\end{array}$ & Scielo & - & - & - \\
\hline $\begin{array}{l}\text { Indicador de } \\
\text { producción }\end{array}$ & $\begin{array}{l}\text { Total de } \\
\text { publicaciones } \\
\text { (búsqueda en } \\
\text { español) }\end{array}$ & $\begin{array}{l}\text { Google } \\
\text { Scholar }\end{array}$ & 5310 & 4260 & 979 \\
\hline \multicolumn{6}{|c|}{$\begin{array}{l}\text { A continuación, haga la comparación del tema, área de conocimiento y/o disciplina de su } \\
\text { profesión entre Colombia y el mundo }\end{array}$} \\
\hline Indicador & Descripción & Fuente & 2018 & 2019 & 2020 \\
\hline $\begin{array}{l}\text { Índice de } \\
\text { actividad }\end{array}$ & $\begin{array}{l}\text { tema, área de } \\
\text { conocimiento } \\
\text { y/o disciplina }\end{array}$ & Scopus & $\begin{array}{l}\text { Índice: } \\
\text { 9/1511=0,0 } \\
05 \\
\text { Total: } 1.511 \\
\text { Colombia: } 9\end{array}$ & $\begin{array}{l}\text { Índice: } \\
\text { 13/1599=0,0 } \\
08 \\
\text { Total: } 1599 \\
\text { Colombia: } 13\end{array}$ & $\begin{array}{l}\text { Índice: } \\
\text { 3/617=0,004 } \\
\text { Total: } 617 \\
\text { Colombia: } 3\end{array}$ \\
\hline $\begin{array}{l}\text { Índice de } \\
\text { actividad }\end{array}$ & $\begin{array}{l}\text { tema, área de } \\
\text { conocimiento } \\
\text { y/o disciplina }\end{array}$ & WOS & $\begin{array}{l}\text { Índice: } \\
\text { 5/1275=0,0 } \\
03 \\
\text { Total: } 1275 \\
\text { Colombia: } 5\end{array}$ & $\begin{array}{l}\text { Índice: } \\
\text { 11/1535=0,0 } \\
07 \\
\text { Total: } 1535 \\
\text { Colombia: } 11\end{array}$ & $\begin{array}{l}\text { Índice: } \\
\text { 1/524=0,001 } \\
\text { Total: } 524 \\
\text { Colombia: } 1\end{array}$ \\
\hline
\end{tabular}


Métricas de Investigación: Cienciometría, Bibliometría y Datos Abiertos

\begin{tabular}{|c|c|c|c|c|c|}
\hline $\begin{array}{l}\text { Tasa de } \\
\text { crecimiento }\end{array}$ & $\begin{array}{l}\text { tema, área de } \\
\text { conocimiento } \\
\text { y/o disciplina }\end{array}$ & Scopus & $\begin{array}{l}\text { Tasa: } \\
\text { 1511/1335 } \\
=1,13 \\
\text { Total 2018: } \\
1511 \\
\text { Total 2017: } \\
1335\end{array}$ & $\begin{array}{l}\text { Tasa: } \\
\text { 1599/1511=1 } \\
\text {,05 } \\
\text { Total 2019: } \\
1599 \\
\text { Total 2018: } \\
1511\end{array}$ & $\begin{array}{l}\text { Tasa: } \\
\text { 617/1599=0,38 } \\
\text { Total 2020: } 617 \\
\text { Total 2019: } \\
1599\end{array}$ \\
\hline $\begin{array}{l}\text { Tasa de } \\
\text { crecimiento }\end{array}$ & $\begin{array}{l}\text { tema, área de } \\
\text { conocimiento } \\
\text { y/o disciplina }\end{array}$ & WOS & $\begin{array}{l}\text { Tasa: } \\
\text { 1275/1232 } \\
=1,03 \\
\text { Total 2018: } \\
\text { 1275 } \\
\text { Total 2017: } \\
1232\end{array}$ & $\begin{array}{l}\text { Tasa: } \\
\text { 1535/1275=1 } \\
\text {,2 } \\
\text { Total 2019: } \\
\text { 1535 } \\
\text { Total 2018: } \\
\text { 1275 }\end{array}$ & $\begin{array}{l}\text { Tasa: } \\
\text { 617/1599=0,34 } \\
\text { Total 2020: } 524 \\
\text { Total 2019: } \\
1535\end{array}$ \\
\hline
\end{tabular}

\section{Conclusiones:}

A partir de lo visto en este documento, es posible afirmar que la violencia doméstica es un campo de estudio que atrae ampliamente los intereses de académicos alrededor del mundo. Este objeto se articula con el campo de estudios de los estudios de género, dominados principalmente por Estados Unidos, el Reino Unido y Canadá, seguidos por Colombia en un puesto 22 a nivel global, llegando a contar incluso con la revista más importante en Latinoamérica (de la Universidad de Los Andes).

Este campo de estudio viene en aumento, teniendo en cuenta que la partir de la década de los 90s se observa un ascenso constante, siendo el año 2019 el de mayor producción académica y siendo los artículos la mayor tipología de publicación.

En Latinoamérica los estudios de la violencia doméstica son dominados por Brasil, seguidos por Perú y Colombia, coincidiendo en ser el artículo su mayor tipología. 